\title{
A trama dos documentos em torno da demarcação da Terra Indígena Igarapé Lourdes
}

\author{
The plot of the documents on the demarcation of the \\ Igarapé Lurdes Indigenous Land \\ Lediane Fani Felzke ${ }^{1}$
}

DOI: https://doi.org/10.26512/rbla.v10i2.20979

Recebido em julho de 2018

Aceito em agosto de 2018

\section{Resumo}

A Terra Indígena Igarapé Lourdes, habitada pelos grupos étnicos Arara e Gavião, está situada no estado de Rondônia, na divisa com o Mato Grosso. A ideia, neste artigo, é compreender as nuances do processo demarcatório nos anos 1970 e trazer alguns dados sobre a invasão e a expulsão de colonos sulistas nos anos 1980, por meio dos registros documentais arquivados na FUNAI/DF e no Museu do Índio/RJ. Quanto à demarcação, a maior parte da terra tradicional dos Ikólóéhj Gavião ficou fora dos limites. Os documentos dão conta que a decisão sobre a área a ser identificada e demarcada foi determinada em Brasília, antes mesmo que a equipe do Grupo de Trabalho chegasse ao então Território de Rondônia. A identificação foi realizada "pelo alto", na medida em que a equipe não conversou com os indígenas Arara e Gavião. A demarcação física teve início no ano de 1976 e foi concluída em 1977. Pouco depois, a terra começou a ser invadida por colonos oriundos do sul e sudeste e mesmo depois da homologação da TI pelo decreto $n^{\circ} .88 .609$ de 09/08/1983, os invasores continuaram no local. Apenas entre 1984 e 1985 foram retirados por iniciativa dos indígenas que então contaram com o apoio da FUNAI e da Polícia Federal. Este processo resultou no deslocamento das aldeias, do interior para o sul da TI a fim de proteger os limites e desestimular novas invasões.

Palavras-chave: Terra Indígena Igarapé Lourdes. Povo Arara. Povo Ikólóéhj Gavião. Identificação e demarcação.

\begin{abstract}
The Igarapé Lourdes Indigenous Land, inhabited by the Arara and Gavião ethnic groups, is located in the state of Rondônia, on the border with Mato Grosso. The idea, in this article, is to understand the nuances of the demarcation process in the 1970s and to bring some data about the invasion and expulsion of southern settlers in the 1980s, through documentary records filed at FUNAI / DF and the Museu do Índio / RJ . As for the demarcation, most of the traditional land of the Ikólóéhj Gavião was off limits. The documents indicate that the decision on the area to be identified and demarcated was determined in Brasília, even before the team of the Working Group arrived at the Territory of Rondonia. The identification was
\end{abstract}

${ }^{1}$ Professora no Instituto Federal de Rondônia (IFRO) Campus Ji-Paraná 
made "at the top", in that the team did not talk to the Arara and Gavião natives. The physical demarcation began in 1976 and was completed in 1977. Shortly after, the land began to be invaded by settlers from the south and southeast and even after the approval of IT by decree no. 88.609 of 09/08/1983, the invaders continued in the place. Only between 1984 and 1985 were they withdrawn on the initiative of the indigenous people who then had the support of FUNAI and the Federal Police. This process resulted in the displacement of villages, from the interior to the south of the TI, in order to protect boundaries and discourage further invasions.

Keywords: The Igarapé Lourdes Indigenous Land. The Arara people. The Ikólóéhj Gavião people. Identification and demarcation.

\section{Contextualizando}

A Terra Indígena Igarapé Lourdes, habitada pelos grupos étnicos Arara e Gavião, está situada no estado de Rondônia, na divisa com o Mato Grosso. A ideia, neste artigo, é compreender as nuances do processo demarcatório nos anos 1970 e os entremeios da invasão e da expulsão de colonos sulistas nos anos 1980 por meio dos registros documentais arrolados no processo FUNAI/ BSB/004.836/1975, arquivado na sede da FUNAI em Brasília e de arquivos do Museu do Índio no Rio de Janeiro. As informações de tais documentos foram complementadas pelos relatos orais de indígenas Ikólóéhj Gavião, interlocutores desta pesquisa.

Este texto foi originalmente escrito para a tese de doutorado ${ }^{2}$ por mim defendida no Programa de Pós-Graduação em Antropologia da Universidade de Brasília e parcialmente publicado no livro "Os Ikólóéhj Gavião: a terra e os outros" (Felzke 2017). Esta versão, mais completa, procura dar conta dos registros oficiais acerca da demarcação da TI, da invasão e da expulsão dos invasores nos anos subsequentes. A demarcação física teve início no ano de 1976 e foi concluída em 1977. A terra começou a ser invadida por não indígenas em fins dos anos 1970, teve seus 185.533 hectares homologados pelo decreto ${ }^{\circ}$. 88.609 de 09/08/1983 e apenas nos anos seguintes os invasores foram retirados.

\section{A chegada ao Igarapé Lourdes}

Depois de percorrer, ao longo de tempos imemoriais, um longo caminho desde as proximidades dos rios Roosevelt e Aripuanã, habitar as cabeceiras dos igarapés que formam o rio Branco e, na sequência, a Serra da Providência, os Ikólóéhj Gavião encontravam-se em 1965, residindo nas margens do igarapé Lourdes, tributário do Rio Machado. Foi naquele local que os primeiros

\footnotetext{
${ }^{2}$ Felzke Lediane. Dança e imortalidade. Igreja, festa e xamanismo entre os Ikólóéhj Gavião de Rondônia. Brasília: PPGAS/DAN/UnB, 2017. Disponível em: http://repositorio.unb.br/ handle/10482/22959
} 
missionários protestantes os encontraram naquele ano ${ }^{3}$. Os mais velhos contam que se surpreenderam com aquele homem muito branco (djála kíhr) que estava ali para falar de Deus e não para comprar borracha ou peles de animais. Afirmam que inicialmente confundiram os missionários com marreteiros ${ }^{4}$. Depois de perscrutar a região e localizar algumas malocas, os missionários da New Tribes Mission retornaram no ano seguinte.

Neste mesmo ano, o SPI também começou a atuar de forma mais significativa na região. Um telegrama do Inspetor Regional desse órgão, datado de 13 de junho de 1966 informa a respeito do deslocamento de uma expedição até o "tuxaua dos Gaviões" para recrutar dez índios a fim de compor a frente de atração dos Cinta Larga em Vilhena. Não descobri se os Ikólóéhj participaram desta expedição, mas suponho que havia alguma proximidade entre eles e o SPI que permitiu a delegação de tal incumbência. Especulo que este vínculo tenha se firmado nas visitas periódicas de oficiais do exército de que fala Vitor Hugo (1959).

Dez dias após esse telegrama, o mesmo inspetor, da $9^{\mathrm{a}}$ Inspetoria Regional do SPI (ININD-9), sediada em Porto Velho, emitiu um novo documento convocando um servidor para "viajar a Vila de Rondônia ${ }^{5}$ para instalar base de atração" no igarapé Lourdes (Museu do Índio/RJ. Acervo. Microfilme 43_2482.). Esse servidor era o senhor Constantino Marques de Almeida que, assim que tomou posse do seu cargo na aldeia Igarapé Lourdes, informou seu chefe que viajaria até Porto Velho, acompanhando os "Tuchaua Tchambete, Fernandes e Carimbéa" a fim de apresentá-los ao chefe da inspetoria, Sr. José de Mello Fiuza, para que esse ouvisse suas reclamações, quais sejam, que "suas terras estão sendo invadidas por garimpeiros e proprietários de minerações". Outro documento, um relatório do senhor Fiuza, informa sobre a situação com indígenas em fins dos anos 1960:

Data de alguns anos passados, os índios Arara e Gaviões, vem sendo orientados, assistidos e também explorados por seringalistas da região do igarapé Lourdes, afluente do Machado. [...]

Ao vizitar (sic) o aldeamento daqueles índios, o nosso representante, comunicou a esta Chefia, a necessidade da presença de um funcionário dêsse (sic) serviço no seio dos mesmos índios, para evitar que

\footnotetext{
${ }^{3}$ A data registrada pelos missionários deste primeiro encontro foi o dia 25 de janeiro de 1965, comemorada até hoje pelos Ikólóéhj como “o dia que a palavra de Deus chegou até nós".

${ }^{4}$ Marreteiros, na Amazônia, são comerciantes que sobem os igarapés trocando mercadorias por produtos extraídos por indígenas, ribeirinhos, pescadores, seringueiros, frequentemente de forma assimétrica.

${ }^{5}$ Vila de Rondônia era o nome de Ji-Paraná até o ano de 1977 quando se torna município e recebe o nome atual.
} 
continuassem sendo explorados por indivíduos inexcrupulosos (sic) e induzidos ao vício de embriaguez alcoolica (sic). (Microfilme 045_00999).

Esse relatório infere que, diante do vácuo da presença do Estado desde os primeiros contatos com os Ikólóéhj e Arara, a "assistência" e "orientação" aos índios ficara a cargo dos seringalistas, para os quais os indígenas trabalhavam extraindo caucho e seringa. O resultado disso, concluiu o inspetor, é que os índios estavam sendo "explorados por indivíduos inexcrupulosos (sic) e induzidos ao vício de embriaguez alcoolica (sic)".

A aproximação de funcionários do SPI junto aos Ikólóéhj teve repercussões negativas para o seringal Santa Maria. Diferente dos primeiros anos de contato com os brancos (possivelmente entre fins dos anos 1940 e início dos anos 1950), a relação entre os indígenas, seringueiros e garimpeiros não era nada amistosa em 1966, a ponto daqueles recorrerem ao SPI para expulsá-los de suas terras. Xabéhr e Fernando, que haviam morado no seringal e falavam minimamente português, eram considerados chefes pelos funcionários do SPI que os chamavam de "Tuchauas". A reclamação desses homens e de Carimbéa desencadeou um processo que resultaria anos mais tarde na demarcação da Terra Indígena Igarapé Lourdes. Por hora, nos interessa registrar que antes mesmo da ação demarcatória, houve mudanças no seringal por conta do falecimento de José Barros, o seringalista que principiou o contato com os indígenas. A empresa seringalista passou a ser intermediada por Fernando Xenepoabáh que assumiu a troca da borracha dos parentes, negociada em Vila Rondônia pelas mercadorias dos brancos. Lamentavelmente Fernando Xenepoabáh teve morte prematura depois de lutar muitos anos contra uma tuberculose.

\section{O processo demarcatório}

Embora a TI esteja completamente regularizada desde sua homologação em 1983, essa questão ainda gera alguma polêmica. Desde meus primeiros contatos com os Ikólóéhj fiquei sabendo que suas terras tradicionais, entre o rio Branco e a face oriental da Serra da Providência, haviam sido preteridas e ficaram fora da área reconhecida pelo Grupo de Trabalho e efetivamente demarcada entre 1976 e 1977. Alguns interlocutores acreditam que os mais velhos, que acompanharam as equipes de demarcação, não souberam ou não quiseram revelar o local exato das malocas ancestrais temendo os ataques dos Zoró, também chamados de Cabeças Secas.

Em outubro e novembro de 2006, durante a coleta de castanha, acompanhei parte da família extensa de Séríhr ${ }^{6}$, filho do zavidjaj Xikov Pí Pòhv, até o

\footnotetext{
${ }^{6}$ Por ocasião da pesquisa de campo realizada pra o mestrado em Desenvolvimento Regional e Meio Ambiente da Universidade Federal de Rondônia.
} 
local onde se encontrava a maloca de seu pai - aldeia Zav Póhj - na Serra da Providência. Naqueles dias convivi com a desolação do grupo pela exclusão desse território ancestral dos limites da área demarcada. Viajando na camionete pelas estradas que atravessavam as imensas fazendas até o acampamento, meus amigos apontaram a direção das aldeias "dos antigos", atualmente tomadas por latifúndios de criação de gado e plantação de soja. Para compreender melhor as circunstâncias da exclusão dessa área, me detive sobre a documentação do processo de identificação, demarcação e homologação da T.I. Igarapé Lourdes. Tais documentos revelaram que os indígenas que acompanharam a demarcação não tiveram nenhuma responsabilidade na exclusão das áreas ancestrais como veremos a seguir.

A partir da correspondência de 1966 para a $9^{\text {a }}$ Inspetoria Regional do SPI (ININD-9) em Porto Velho, informando que as terras dos índios estavam sendo invadidas por seringueiros, garimpeiros e donos de mineradoras, o Inspetor Regional, senhor Fiúza, solicitou ao governador do Território Federal de Rondônia para que fosse "preservada" uma área de terras "devolutas", totalizando 97.500 ha para serem futuramente demarcadas pelo SPI. O croqui entregue ao governador incluía o Rio Riachuelo que ficou de fora da área efetivamente demarcada dez anos depois.

$\mathrm{Na}$ sequência dessa solicitação, houve uma operação de evacuação de seringueiros e garimpeiros da área do Igarapé Lourdes (Microfilme 043_02505). E embora nem todos saíssem naquela oportunidade, foram apreendidos cinco mil quilos de caucho e doze pelas de seringa extraídas pelos indígenas por ordem do seringalista. A interferência no SPI no sentido de coibir a ação de seringueiros e exploradores de minério na região provocou a insatisfação daqueles. A presença do SPI - FUNAI a partir de 1967 - resultou na transformação da então frente de atração Igarapé Lourdes em Posto Indígena.

Em 02 de abril de 1971, foi publicada a portaria 06/N que criou o Posto Indígena Igarapé Lourdes (PIN) no então Território Federal de Rondônia para "prestar uma assistência efetiva aos grupos indígenas Suruí, Arara e Gavião". A criação do PIN atraiu mais ainda os grupos familiares dos indígenas dispersos pelo território, na medida em que essa aldeia se transformou em um centro de operações com escola, posto médico, rádio e gerador de energia.

Alguns anos mais tarde, em janeiro de 1974, por meio do decreto $\mathrm{n}^{0} 73.563$, a FUNAI declarou interditadas "temporariamente, para efeito de atração dos grupos indígenas Cinta Larga, Suruí, Arara, Gavião e Erikbatsa (sic.), as áreas situadas no Estado do Mato Grosso e no Território Federal de Rondônia”. Nesta área interditada encontrava-se a terra de ocupação tradicional dos Gavião, entre a margem esquerda do Rio Branco e a Serra da Providência. A interdição dessa área deu início ao processo que culminou com a homologação da TI Igarapé

${ }^{7}$ Como eram chamados os Zoró na ocasião. 
Lourdes em 1983.

No entanto, grande parte da área interditada não foi demarcada e, após a demarcação, o decreto 82.064 de 03 de agosto de 1978 "declara sem efeito a interdição de parte da área a que se refere o decreto $\mathrm{n}^{\mathrm{0}} 73.562$, de 24 de janeiro de 1974...”, ou seja, exatamente a terra tradicional dos Ikólóéhj, que ficara fora da demarcação, foi desinterditada por este decreto. Trata-se da região colorida de vermelho na imagem abaixo, uma reprodução fotográfica do mapa da FUNAI que acompanha o processo de demarcação da TI Igarapé Lourdes..

O inexplicável é que, apesar das malocas dos Ikólóéhj terem sido identificadas na área em vermelho, como demonstram os triângulos ali dispostos, a demarcação ignorou as aldeias e seguiu o limite natural da Serra da Providência que identifica a divisa entre Rondônia e Mato Grosso, para fins de demarcação. O que deveria ser uma área de demarcação contínua, desde os parque Aripuanã (em azul) dos Cinta Larga, até a TI Igarapé Lourdes, passando pelas demais terras Cinta Larga, Zoró (que ainda não haviam sido contatados) e Suruí, foi fraturada pelas fazendas que hoje cobrem de bois e capim os lugares onde moravam os ascendentes dos Ikólóéhj Gavião.

Figura 1: Mapa constante do processo da T.I. Igarapé Lourdes



Fonte: Processo FUNAI/BSB/004.836/1975 de 10 de outubro de 1976.

Setor de documentação e arquivos da sede da FUNAI.

Sebirop, cacique dos Ikólóéhj Gavião, contou que nos anos 1970, ele e 
outros indígenas participaram ativamente do contato com os Suruí. Foi naquele contexto que estabeleceram amizade com Apoena Meirelles, então sertanista da FUNAI. Assim que retornaram da frente de atração, perceberam que precisavam garantir sua terra, pois a fronteira agrícola estava se aproximando perigosamente das "terras dos índios". A demarcação administrativa teve início em 1976 sendo levada a efeito pela empresa PLANTEL S/A, com sede em Goiânia/GO, e foi concluída em meados de 1977. A área demarcada seguiu a orientação do grupo de trabalho instituído em 1975 para "[...] delimitar as áreas necessárias ao Posto Indígena Igarapé Lourdes, aos Postos Indígenas de Atração 7 de Setembro e Roosevelt, bem como outras áreas ocupadas por grupos indígenas porventura localizados na Área I, constante do Decreto n ${ }^{\circ} 73.562$, de 24 de janeiro de 1974".

Lembro que o decreto citado pela portaria de demarcação havia interditado uma área quase contínua, para fins de estudo, desde a terra dos Cinta Larga até o Rio Machado. O grupo de trabalho que elaborou os estudos para a demarcação de tais áreas era formado por cinco pessoas: o titular da $8^{\mathrm{a}}$ Delegacia Regional da FUNAI, um antropólogo, uma engenheira agrônoma, um advogado e um agrimensor.

O relatório do delegado da $8^{\text {a }}$ Delegacia Regional da FUNAI sobre a missão do GT é substancialmente revelador sobre os conflitos de terra que já se avizinhavam na Amazônia meridional nos anos 1970 em função da afluência massiva de migrantes oriundos do sul e sudeste do país atendendo aos apelos do governo militar que ostentava o slogan "terras sem homens para homens sem terra". Tal relatório informa dos conflitos entre posseiros e índios Suruí e das ocupações ilegais por fazendas nas terras dos Cinta Larga e solicita urgente demarcação das terras desses povos a fim de garantir a integridade física e social dos índios e também dos agricultores. Repleto de detalhes sobre as visitas do GT às aldeias desses povos indígenas, no entanto, é exíguo quando trata da terra dos índios Arara e Gavião.

Replico abaixo as únicas referências que o texto faz ao então PI Igarapé Lourdes. Ao descrever o périplo percorrido, é apenas na página sete que o relator informa:

No dia seguinte pela manhã decolamos e sobrevoamos (grifo meu) a área do PI IGARAPÉ LOURDES descendo o RIO MACHADO até a confluência com o Igarapé Azul. A margem direita deste Rio, consequentemente, área Indígena, existem algumas fazendas (seringais), porém mais para o interior ou mesmo próximo ao Posto nada ainda existe.

Após completar o circuito retornamos a Porto Velho com a missão cumprida. Nesse mesmo dia demos início a confecção dos relatórios e Memoriais Descritivos das áreas a serem propostas para os nossos índios. 
Por sua vez, o relatório de duas páginas da engenheira agrônoma que compunha o GT, registra no penúltimo parágrafo:

Depois do P.I. ROOSEVELT fomos até o P.I. IGARAPÉ LOURDES, onde sobrevoamos (grifo meu) e limitamos a área de acordo com os limites anteriormente previsto (sic). A topografia de toda a reserva é formada de $50 \%$ de terrenos planos e $50 \%$ de terrenos ondulados. A área próxima ao posto, onde os índios utilizam para suas lavouras é formada de terrenos planos, as margens do Rio Lourdes.

O relatório antropológico, por sua vez, se limitou a sugerir abertura de "cantinas" pela FUNAI para desestimular o deslocamento dos indígenas aos núcleos habitacionais abertos pelos colonos, e reforçou que "tal raciocínio é válido tanto para os Suruí do Posto Sete de Setembro como para os Cinta Larga do Roosevelt e os Arara e Gavião do P.I. Igarapé Lourdes". Essa foi a única referência do relatório antropológico aos Arara e Gavião.

O Memorial Descritivo para a demarcação do P.I. Igarapé Lourdes, produzido pelo agrimensor do GT, e que acompanhou o relatório, indicou a existência de 197 indígenas, embora sem informar a origem desse dado na medida em que a equipe não esteve em solo na terra dos Arara e Gavião, mas tão somente sobrevoou a área como vimos nos relatos acima. O memorial explicitou ainda que a área a ser demarcada fosse limitada a leste pelo traçado da Serra da Providência, como podemos ver no texto do memorial que antecede o mapa:

Partindo da confluência do Igarapé Água azul com o Rio JI-PARANÁ ou MACHADO no ponto de coordenadas aproximadas de $10^{\circ} 13^{\prime} 00^{\prime \prime} \mathrm{S}$ e 6153'30”W; segue no sentido Leste pelo Igarapé Água azul acima até sua nascente ou cabeceira, daí com o rumo de $45^{\circ} 00^{\prime} 00^{\prime} \mathrm{NE}$ até encontrar a fronteira RONDÔNIA MATO GROSSO, (SERRA DA PROVIDÊNCIA) (grifo meu) daí no sentido Sul pela fronteira acima até encontrar a cabeceira do Igarapé da Prainha no ponto de coordenadas aproximadas de $10^{\circ} 49^{\prime} 00^{\prime \prime} \mathrm{S}$ e $61^{\circ} 31^{\prime} 15^{\prime \prime} \mathrm{W}$, daí por este Igarapé abaixo até encontrar a confluência com o Igarapé Água Azul ponto de partida.

Este documento indica que o Grupo de Trabalho, ao iniciar os procedimentos para verificar as áreas a serem demarcadas, já sabia qual seria o traçado da TI Igarapé Lourdes, antes de realizar a pesquisa in loco. Mesmo sabendo da interdição das terras entre a Serra da Providência e o Rio Branco pelo decreto de 1974, em nenhum momento cogitou-se uma inspeção mais detalhada dessa área. A equipe não foi até os índios e nem mesmo verificou a existência de aldeias a leste da Serra da Providência. Foi sobrevoando, ou seja, "pelo alto", que os técnicos identificaram a área a ser demarcada. E, embora os funcionários do Posto Indígena Igarapé Lourdes tenham orientado os Ikólóéhj a "falar onde 
é a terra de vocês", quando a equipe de demarcação chegou até a aldeia em 1976, os limites já tinham sido determinados pelo GT em 1975. Esse GT, por sua vez, já sabia que a área que deveria constar no Memorial Descritivo era aquela em que "nada ainda existe". As terras entre o Rio Branco e a Serra da Providência, onde havia malocas dos Ikólóéhj, já estavam reservadas a outros fins pelo Estado brasileiro como comprova a instalação de grandes latifúndios na região.

Não houve insistência, na época, da parte dos Ikólóéhj, em incluir a região a leste da Serra da Providência na terra demarcada por várias razões. Uma delas é que o GT que definiu os limites não lhes deu essa oportunidade, outra era o receio de choques com o povo Zoró que já era conhecido da FUNAI desde 1973 conforme podemos constatar pela Informação $n^{\circ} 006 / C O A M A / 1976^{8}$ :

Considerando que as informações que a COAMA possui sobre a localização dos Zoró são antigas (1973), seria oportuno efetuar-se um sobrevôo na área compreendida entre os rios Branco e Fortuna de forma a, identificando-se a posição atual dos aldeiamentos (sic) desse grupo indígena, poder-se definir sua área de ocupação.

A trama de documentos de toda ordem que envolve o processo de demarcação da Terra Indígena Igarapé Lourdes deixa transparecer que a área entre a Serra da Providência e o Rio Branco, terra tradicionalmente ocupada pelos Ikólóéhj estava, desde o início dos procedimentos, destinada a outros usos. Embora interditada em 1974, não estava nos planos do Governo Federal mantê-la para os índios. Se assim fosse, o GT instituído teria atentado para as aldeias existentes na área. Como já estava pré-determinado quais áreas deveriam ser demarcadas, não houve interesse de conversar com os Ikólóéhj para saber sobre suas aldeias e suas terras tradicionais.

Dois registros corroboram esse entendimento. O primeiro consta na introdução do "Relatório de Missão" do GT e diz o seguinte:

Após uma explicação detalhada na área, com apresentação de vários mapas em diversas escalas, incluindo os de navegação utilizados pela F.A.B, por mim adquiridos no Rio, chegamos a um comum acordo da área necessária a sobrevivência dos índios nos Postos Indígenas: IGARAPÉ LOURDES (grifo meu), 7 de SETEMBRO e ROOSEVELT, sem nenhuma preocupação do que por ali pudesse existir, INCRA, ITAPORANGA, GRILHEIROS (sic), etc.

O segundo registro refere-se ao pedido do presidente da FUNAI ao Ministro do Interior, datado de 26/06/1978, de desinterdição da área referida acima. Em 22 de março do mesmo ano, um assistente da Procuradoria da República

${ }^{8}$ COAMA: Coordenação da Amazônia da FUNAI. 
concedeu um parecer no sentido de que não havia provas suficientes de que a área estava apta a ser desinterditada, ou seja, havia dúvidas quanto à existência ou não de indígenas naquela região. Menos de dois meses depois, em bilhete manuscrito, o Chefe da Divisão de Registro Patrimonial da FUNAI escreveu ao diretor da DGPI (Departamento Geral de Patrimônio Indígena), em resposta ao parecer da Procuradoria da República, nos seguintes termos: "Os motivos determinantes da desinterdição da área objeto deste processo não constam do memorandum do sr. Presidente [...]. Apenas cumprimos uma ordem superior" (grifo meu). Em maio, o diretor substituto do Departamento Geral de Operações (DGO) da FUNAI se manifestou a respeito e justificou, em texto manuscrito, a desinterdição da área: "De qualquer forma, esclareço, que, quando o Exmo. Sr. Presidente determina a desinterdição de uma área, razão precípua é sempre a comprovada ausência de índios. Na falta de outra [razão], esta me parece suficiente". No dia seguinte a esse manuscrito, o chefe de gabinete da FUNAI informou que: "com a interdição da referida área, considerada necessária aos trabalhos de atração, a outra parte, (Dec. 73.562/74), ficou sem utilidade para a FUNAI (sem índios) e, por isso, deverá ser liberada".

Um breve relatório datado de 03 de fevereiro de 1978 de Apoena Meirelles, então assistente do DGO (Departamento Geral de Operações), é emblemático sobre o assunto. Referindo-se as áreas que circundam a localização das malocas dos Zoró, Apoena registra:

Colonos: Não existem colonos, pois as terras dos Zoros estão cercadas por grandes latifúndios, que dessa forma não permitem que as frentes de colonização entrem nas suas terras, haja visto que os grandes grupos empregam mais de 300 trabalhadores nas épocas das derrubadas, e contam com bem armados 'fiscais', o que intimida os colonos.

Agropecuárias: São incontáveis as existentes nas margens dos rios Branco e Roosevelt, com extensões que variam de 60.000 ha 300.000 ha, tais como a Castanhal, Roosevale, Concisa, e por aí afora. (Grifo meu)

O relato de Apoena Meirelles esclareceu que, em 1978, as margens do rio Branco, terra tradicional dos Ikólóéhj já estavam ocupadas por empresas "Agropecuárias" que eram guardadas por "bem armados "fiscais", o que impedia, inclusive, o avanço da frente colonizadora que invadia a terra dos Suruí naqueles anos. Ou seja, antes mesmo do decreto de desinterdição da área, a terra já estava ocupada por latifúndios. Essa foi, seguramente, a principal razão que ocasionou aos Ikólóbéhj a perda do seu território tradicional.

Se, para o Estado brasileiro essa questão foi resolvida pelo decreto 82.064 de 03 de agosto de 1978 que "[d]eclara sem efeito a interdição de parte da área a que se refere o Decreto $\mathrm{n}^{\circ} 73.562$, de 24 de janeiro de 1974, alterado 
pelo decreto $\mathrm{n}^{\circ} 77.033$, de 15 de janeiro de 1976, e dá outras providências", para os Ikólóéhj essa é uma questão em aberto. O deliberado desconhecimento dos agentes do Estado a respeito do seu território repercutiu na supressão das áreas tradicionalmente ocupadas e, assim, as aldeias localizadas fora da área demarcada tiveram que ser transferidas. Parece-me que essa digressão em torno desses documentos esclarece em boa medida os motivos que levaram os Ikólóéhj a perderem suas terras, ficando assim limitados aos 185 mil hectares que constituíam, em sua maior parte, território dos Arara.

\section{Ameaça da perda da terra demarcada}

Mesmo com a terra devidamente demarcada, desde 1977, colonos provenientes das regiões sul e sudeste do país, passaram ocupar a área sul da T.I. Agindo de má fé, pois sabiam tratar-se de Terra Indígena, algumas pessoas ligadas a órgãos públicos, marcaram lotes e venderam as "marcações" aos migrantes recém chegados a Rondônia. Em 1984 e 1985, sem que a FUNAI e a Polícia Federal resolvessem o assunto, os Ikólóéhj e Arara tomaram a iniciativa de expulsar os invasores. Diante da determinação dos índios em não perder parte da já exígua terra demarcada, os órgãos do Estado passaram a agir. $\mathrm{O}$ cadastro do INCRA informa que aproximadamente 400 famílias estavam ocupando irregularmente a T.I. Os colonos foram retirados e parte deles foi reassentada no município de Machadinho, no estado de Rondônia. Mas a ameaça de novas invasões nas picadas já abertas era uma constante. Diante dessa insegurança, os Ikólóéhj e os Arara que habitavam aldeias no interior da T.I., resolveram deslocar-se para o limite sul e assim coibir novas invasões 9

Em decorrência desse deslocamento, a aldeia Igarapé Lourdes que até então se constituía na principal aldeia dos Ikólóéhj foi perdendo sua importância estratégica. $\mathrm{O}$ acesso por estrada para a cidade de Ji-Paraná tornou a área sul da T.I. mais atrativa em muitos aspectos. Nessa área foi fundada a aldeia Ikólóéhj, que em pouco tempo recebeu o status de "aldeia central" dos Gavião. Neste período, Sebirop já era reconhecido como cacique, e sua atuação na expulsão dos invasores, juntamente com a de seu irmão Padág, legitimou sua liderança que havia iniciado ainda na aldeia Igarapé Lourdes.

Com sua fundação a aldeia Ikólóéhj concentrou a grande parte das famílias que havia saído do Lourdes ${ }^{10}$. Mas essa concentração durou pouco tempo e aos

\footnotetext{
${ }^{9}$ Os anos 1970 e 1980 assistiram a uma violenta ocupação do Território de Rondônia. O Estado brasileiro estimulou a migração de camponeses das regiões Sul e Sudeste atravéspor meio de projetos de assentamento agrícola que foram insuficientes para atender a demanda. Para detalhes sobre esse processo ver Felzke et.al (2014). Diante disso as terras indígenas passaram a ser alvo de indivíduos que agiam de má fé e vendiam lotes aos colonos recémchegados.

${ }^{10}$ Outras ocuparam as colocações dos colonos que foram expulsos da T.I.
} 
poucos a dinâmica residencial pautada em grupos familiares - que estrutura a organização social - voltou a operar provocando inúmeras subdivisões e o surgimento de várias aldeias. Atualmente são dezessete as aldeias Ikólóéhj, quinze delas localizadas na área sul da T.I, como mostra o mapa a seguir.

Figura 2: Aldeias da área sul da Terra Indígena Igarapé Lourdes.

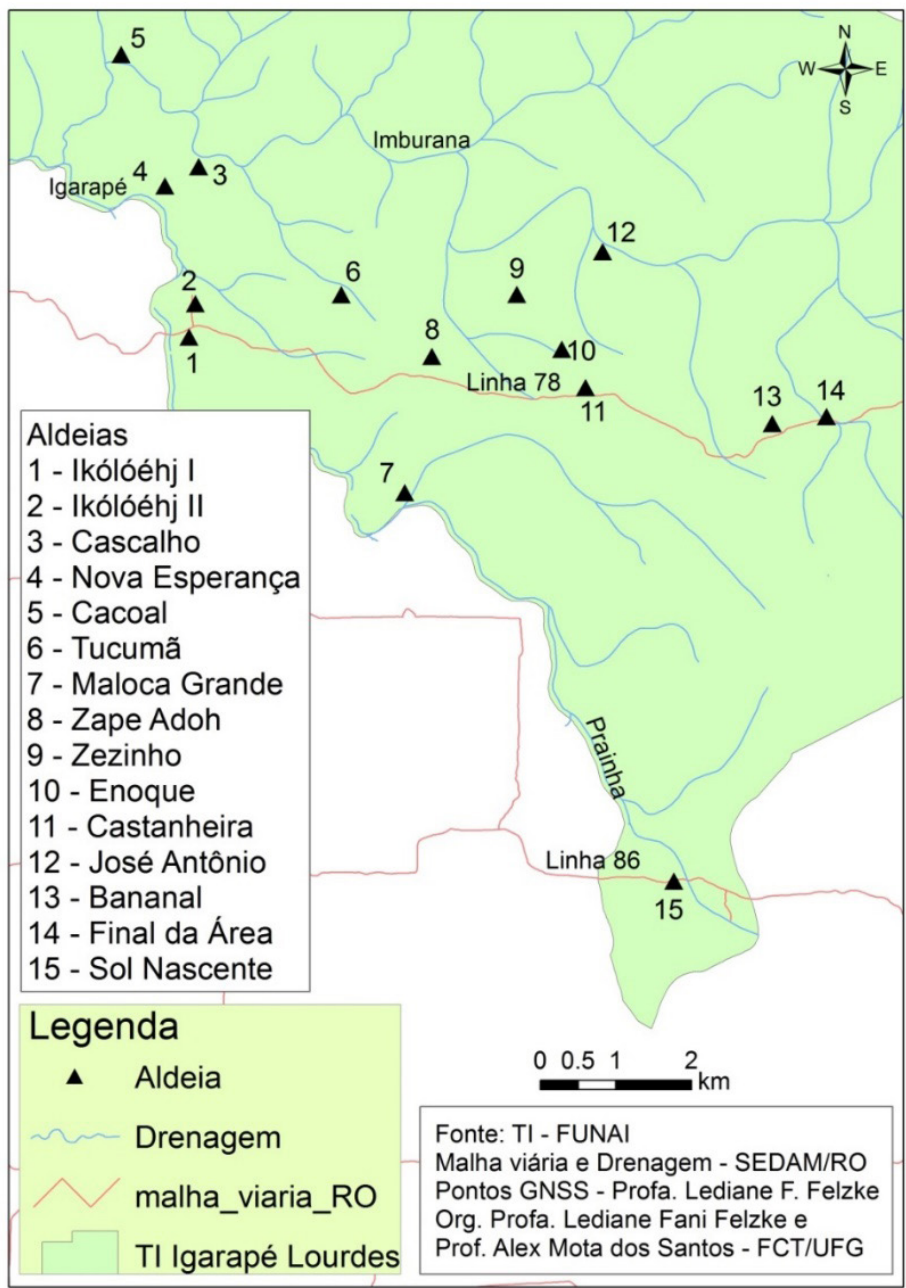

A cada ano que passa, novas famílias deixam a aldeia Igarapé Lourdes e se mudam para perto do Ikólóéhj. O principal argumento utilizado é a dificuldade de acesso. Embora haja uma estrada que ligue essa aldeia até o Ikólóéhj, ela permanece a maior parte do ano intransitável. No período chuvoso é impossível percorrer seus cinquenta quilômetros por terra, apenas a via fluvial pode ser utilizada tornando oneroso o transporte de pessoas e mercadorias. Atualmente, cerca de noventa pessoas, treze famílias nucleares, ainda residem na aldeia Igarapé Lourdes. Algumas delas, no entanto, embora mantenham suas casas e 
constem no registro da SESAI como residentes nessa aldeia, passam a maior parte do ano em outros lugares.

Se por um lado, a presença do posto de saúde, da escola com ensino médio e da igreja - sede das festas - estimula a manutenção das residências no Ikólóéhj, a tendência é que os grupos domésticos se dispersem cada vez mais pelas redondezas. Conforme apontei acima, o padrão residencial em unidades pequenas e autônomas é estruturante na socialidade Ikólóéhj e leva às frequentes divisões de aldeias. O mapa abaixo, elaborado por um jovem indígena, mostra as aldeias da área que havia sido invadida.

Figura 3: Configuração das aldeias pelo ponto de vista de um jovem $i k \underline{o} \underline{\text { lóéhj. }}$

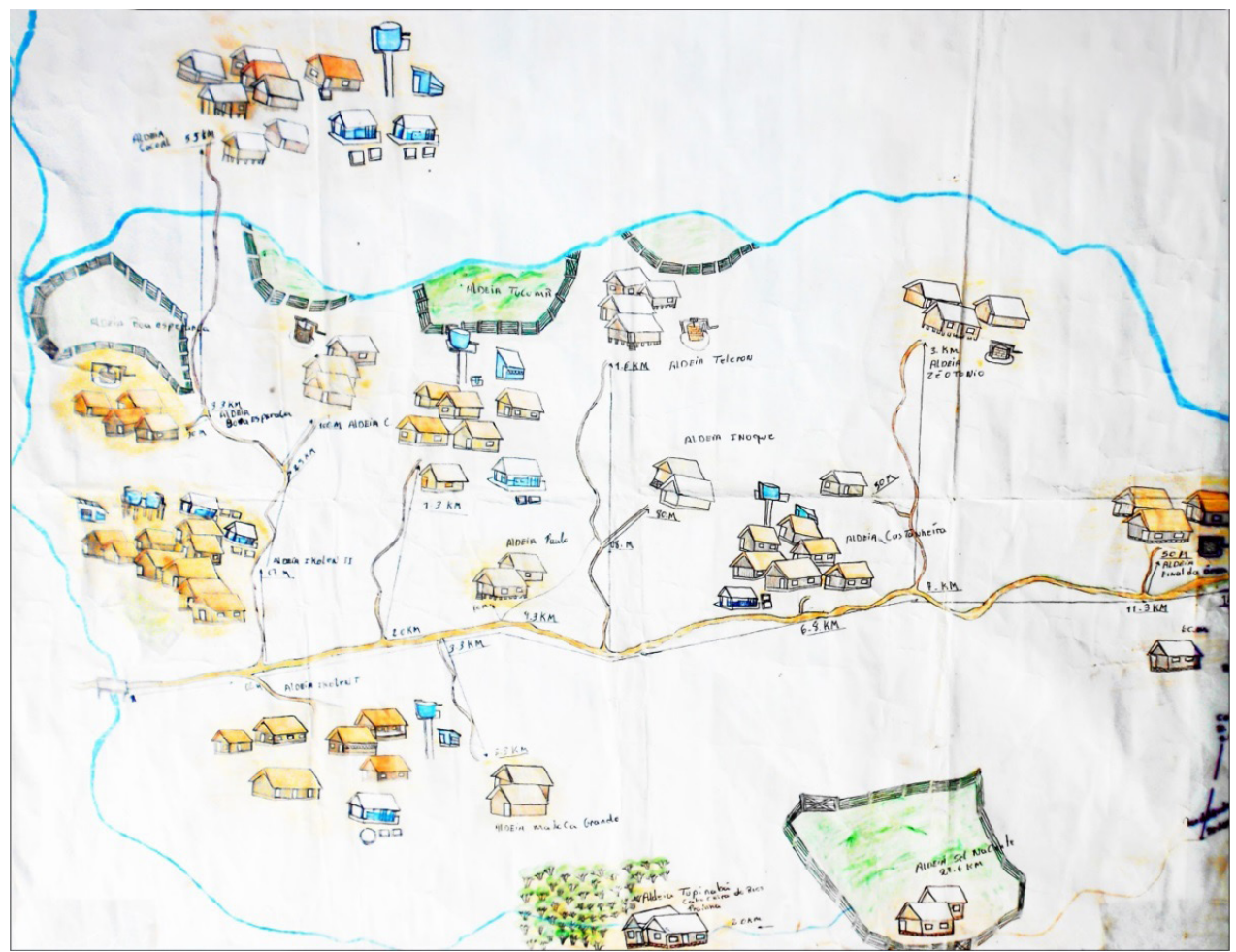

Fonte: Mapa das aldeias da parte sul da T.I. elaborado por Thiago Xípo, filho do senhor Madjikihr, morador da aldeia Tucumã.

\section{Considerações finais}

Com os dados documentais analisados nesse artigo, perde força a versão disseminada entre alguns indígenas de que os mais velhos não explicaram corretamente onde estavam as terras tradicionais para a equipe de demarcação, o que teria causado a perda do território tradicional. Vimos que, ao chegar às aldeias a equipe de demarcação da empresa Plantel S/A chegou às aldeias, já estava ciente de que a divisa territorial leste seria a Serra da Providência. 
Os documentos indicam que isso já estava determinado antes mesmo do GT sobrevoar a área para produzir o Memorial Descritivo da Terra Indígena Igarapé Lourdes. Dessa forma os Ikólóéhj perderam a maior parte de suas terras tradicionais para os latifúndios instalados na face leste da Serra da Providência e passaram dividir o território com o povo Arara que habita as margens do rio Machado desde tempos imemoriais.

\section{Referências}

Felzke, Lediane. Dança e imortalidade. Igreja, festa e xamanismo entre os Ikólóéhj Gavião de Rondônia. Brasília: PPGAS/DAN/UnB, 2017. Disponível em: http:// repositorio.unb.br/handle/10482/22959 . Os Ikólóéhj Gavião: a terra e os outros. São Leopoldo/RS: Oikos, 2017.

Felzke, Lediane Fani et.al. Memória e resistência na migração para a Amazônia: o caso de Nova Londrina em Ji-Paraná, estado de Rondônia, Brasil. Mundo Agrário, v. 15, n. 30, 2014.

FUNAI. Terra Indígena Igarapé Lourdes. Processo número FUNAI/BSB/004.836/1975.

Hugo, Victor. Desbravadores. Humaitá: Missão Salesiana de Humaitá. 1959.

Museu do Índio. Acervo. Microfilme 43_2482. Rio de Janeiro.

. Acervo. Microfilme 43 02505. Rio de Janeiro.

. Acervo. Microfilme 45_00999. Rio de Janeiro. 